\title{
Adenovirus E1A Coding Sequences That Enable ras and pmt Oncogenes To Transform Cultured Primary Cells
}

\author{
BRAD ZERLER, ${ }^{1}$ BETTY MORAN, ${ }^{1}$ KAZUO MARUYAMA, ${ }^{2}$ JOHN MOOMAW, ${ }^{3}$ TERRI GRODZICKER, ${ }^{1}$ \\ AND H. EARL RULEY ${ }^{2 *}$ \\ Cold Spring Harbor Laboratory, Cold Spring Harbor, New York 11724' Center for Cancer Research and Department of \\ Biology, Massachusetts Institute of Technology, Cambridge, Massachusetts 02139²; and Department of Bacteriology and \\ Immunology, University of North Carolina, Chapel Hill, North Carolina $27514^{3}$
}

Received 23 August 1985/Accepted 8 December 1985

\begin{abstract}
Plasmids expressing partial adenovirus early region 1A (E1A) coding sequences were tested for activities which facilitate in vitro establishment (immortalization) of primary baby rat kidney cells and which enable the T24 Harvey ras-related oncogene and the polyomavirus middle $T$ antigen (pmt) gene to transform primary baby rat kidney cells. E1A cDNAs expressing the 289- and 243-amino acid proteins expressed both E1A transforming functions. Mutant $h r A$, which encodes a 140-amino acid protein derived from the amino-terminal domain shared by the 289- and 243-amino acid proteins, enabled ras (but not pmt) to transform and facilitated in vitro establishment to a low, but detectable, extent. These studies suggest that E1A functions which collaborate with ras oncogenes and those which facilitate establishment are linked. Furthermore, E1A transforming functions are not associated with activities of the 289-amino acid E1A proteins required for efficient transcriptional activation of viral early region promoters.
\end{abstract}

The early region $1 \mathrm{~A}(\mathrm{E} 1 \mathrm{~A})$ transcription unit of human adenovirus encodes products important in oncogenic transformation. In particular, E1A expresses activities which extend the growth potential of cultured primary cells, resulting in cells capable of growing indefinitely in vitro as established cell lines (24). In addition, E1A can collaborate with both viral genes and cellular oncogenes to transform cultured primary cells (45).

Two lines of evidence suggest that E1A establishment functions are linked to the ability to collaborate with other oncogenes in primary cell transformation. (i) Neither the gene encoding the polyomavirus middle $\mathrm{T}$ antigen $(\mathrm{pmt})$ nor the Harvey ras-related oncogene isolated from T24 bladder carcinoma cells (T24 Ha-ras) is individually able to transform certain primary rodent cells after DNA-mediated gene transfer $(28,33,39,42,45)$, whereas these genes readily transform cells from a variety of established lines $(7,17,28$, $39,42,55)$. (ii) Genes other than E1A, which collaborate with the T24 Ha-ras oncogene in primary cell transformation, namely, polyomavirus large $\mathrm{T}$ antigen (plt), avian myelocytomatosis virus, $m y c$, and p53 (13, 33, 40), also facilitate the establishment of primary cells $(28,43,46)$.

The physiological basis for E1A-induced establishment of primary rodent cells is presently unknown; moreover, the role of individual E1A proteins has not been determined. Coding sequences for three related proteins are generated by differential splicing of adenovirus E1A transcripts during lytic infection. The 289- and 243-amino acid proteins are encoded by $13 \mathrm{~S}$ and $12 \mathrm{~S}$ mRNAs, respectively. Since the splicing process maintains the reading frames of both mRNAs (41), the 289- and 243-amino acid proteins differ only by 46 internal amino acids. The third E1A transcript, a 9S mRNA, is most abundant late during lytic infection and has not been detected in adenovirus-transformed cells.

Several biological activities for the E1A proteins have

\footnotetext{
* Corresponding author.
}

been described, but it is not known whether any of these are relevant to transformation. In particular, adenovirus genes are coordinately regulated during lytic infection, and E1A is required for efficient transcription of viral early region genes $(4,29)$. E1A proteins also influence the transcription of a number of cellular genes, both resident within the genome and carried on transfected plasmids $(1,5,21,30,34,47,53$, $54,56)$. Finally, E1A expression is required for efficient adenovirus infection of quiescent cells (37), stimulation of cellular DNA synthesis $(3,52)$, and cell cycle progression (3).

It is not known whether one or several biochemical activities are responsible for these biological effects. However, one might speculate that transcriptional effects, loss of cell cycle controls, chromosome abnormalities, collaboration with oncogenes, and establishment of primary cells could all be manifestations of the same biochemical activity.

In the present study, plasmids capable of expressing limited portions of E1A coding sequences were tested for their ability to collaborate with transforming genes in primary cell transformation and to promote the establishment of primary cells in vitro. Analysis of E1A transforming functions by cotransfection with viral and cellular transforming genes offers several advantages over analysis of viral transformation. In particular, the transforming abilities of mutant E1A transcription units can be assessed in the absence of either viral cytotoxicity or transcriptional effects such as the autoregulation of E1A or the activation of E1B.

The experiments reported here addressed related goals. We localized E1A functions important in primary cell transformation and examined the linkage between E1A functions which facilitate establishment of cultured primary cells and those which collaborate with transforming genes in primary cell transformation. Since the biochemical activities of E1A proteins are presently unknown, close associations among two or more of the biological effects induced by E1A will help clarify whether these result from a single biochemical activity. 

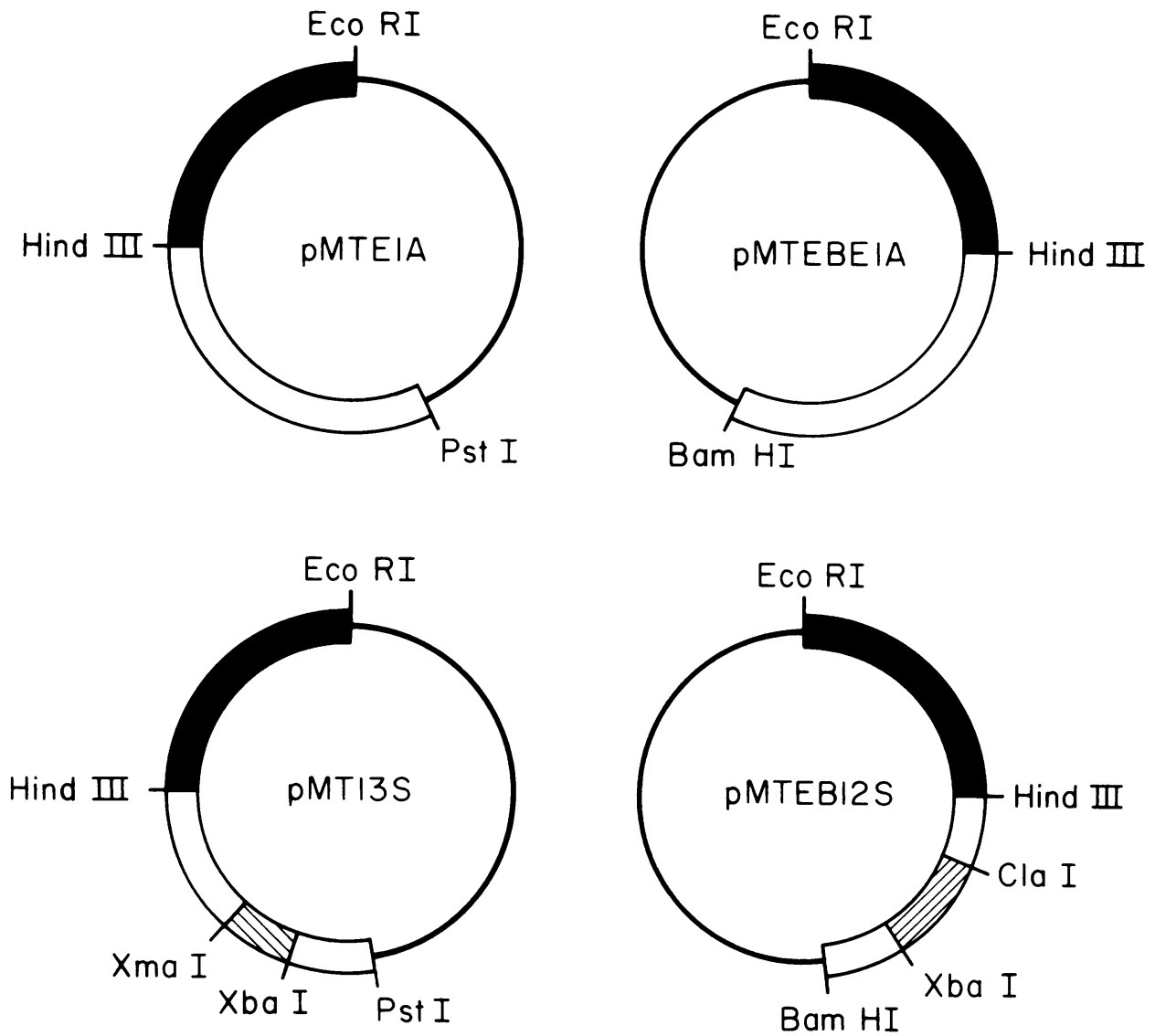

FIG. 1. Construction of E1A $13 \mathrm{~S}$ and 12S cDNA expression plasmids. pMTE1A contains Ad5 sequences (open bar) extending from a HindIII linker inserted near the transcriptional start site (estimated at nt 493) to the viral PstI site at nt 1834. E1A sequences were joined to a 1.4-kilobase fragment containing the promoter of the mouse metallothionein I gene (blackened bar). A BgllI site near the metallothionein promoter was converted to a HindIII site for this purpose. pMTEBE1A is similar to pMTE1A except that the PstI site was converted to a BamHI site. The plasmid vector for both constructs was pAT153 (thin line). 13S and 12S cDNA clones were isolated from an early Ad2 library (15) by hybridization to a ${ }^{32} \mathrm{P}$-labeled $\mathrm{Hpal}$ E fragment probe (0 to 4.3 map units). Positive clones were analyzed by restriction endonuclease cleavage, and the region between the viral $C l a I$ and $X b a I$ sites was sequenced. pMT13S and pMTEB12S were constructed by exchanging cDNA sequences (hatched bar) contained within an XmaI-XbaI fragment (13S) or a ClaI-XbaI fragment (12S) with the corresponding genomic sequences of pMTE1A and pMTEB1A.

\section{MATERIALS AND METHODS}

Cells and plasmid DNAs. Cultures of primary baby rat kidney (BRK) cells were prepared and transfected by the DNA-calcium phosphate coprecipitation method as described previously (45). Plasmids not described in the text contained the following viral and cellular sequences: pT24, the activated Ha-ras 1 gene isolated from human T24 bladder carcinoma cells (17); pPyMT, a modified polyomavirus genome which expresses only the middle $\mathrm{T}$ antigen protein (55); pHr1 and pHrA, adenovirus 5 (Ad5) E1A sequences contained in the BalI I fragment (0.7 to 5.7 map units) of Ad5 $h r 1$ and $h r 440$ host range mutants, respectively (D. Solnick, unpublished data); and $d / 343$, Ad5 E1A sequences extending between nucleotides (nt) 1 and 1834 but deleting nt 621 and 622 (P. Hearing, unpublished data).

Analysis of cellular RNA. RNA was isolated by the guanidine thiocyanate method of Chirgwin et al. (11). Total cellular RNA $(20 \mu \mathrm{g})$ was analyzed as described previously (61) after hybridization to ${ }^{32} \mathrm{P}$-labeled RNA probes $\left(10^{4} \mathrm{cpm}\right.$; Chrenkov) generated in vitro with SP6 polymerase. RNaseprotected fragments were fractionated on $5 \%$ polyacrylamide gels.
Hybridization, selection, and in vitro translation of E1A RNAs. A 200- $\mu$ g sample of cytoplasmic RNA was hybridized to pHEB4 DNA immobilized on nitrocellulose filters. pHEB4 is a plasmid containing an Ad2 E1A DNA fragment extending from the BalI site at base pair 267 to the $\mathrm{HpaI}$ site at base pair 1569 . RNA was eluted and translated with a rabbit reticulocyte system as described by Lewis and Mathews (35) and Solnick and Anderson (51). Polypeptides synthesized in the presence of $\left[{ }^{35} \mathrm{~S}\right]$ methionine (New England Nuclear Corp.) were fractionated on $15 \%$ sodium dodecyl sulfate-polyacrylamide gels and detected by fluorography.

Transient expression assays. Transfections were performed by using a modification of the calcium phosphate coprecipitation technique $(20,59)$. HeLa cells at approximately $75 \%$ confluence were fed with Dulbecco modified Eagle medium containing $5 \%$ fetal calf serum approximately $4 \mathrm{~h}$ before transfection. A $20-\mu \mathrm{g}$ portion of DNA $(5 \mu \mathrm{g}$ of pKCAT23 [a gift from N. C. Jones] plus $5 \mu \mathrm{g}$ of E1A plasmid and $10 \mu \mathrm{g}$ of high-molecular-weight salmon sperm DNA) was suspended in $250 \mu$ l of $2 \times$ HEPES-buffered saline ( $\mathrm{pH} 7.05)$ containing the following (grams per liter): HEPES ( N-2hydroxyethylpiperazine- $N^{\prime}$-2-ethanesulfonic acid), 10; 
$\mathrm{NaCl}, 16 ; \mathrm{KCl}, 0.74 ; \mathrm{Na}_{2} \mathrm{HPO}_{4}, 0.25 ;$ and glucose, 2. An equal volume of $0.25 \mathrm{M} \mathrm{CaCl}_{2}$ was added dropwise, and the mixture was allowed to form a precipitate for $10 \mathrm{~min}$ at room temperature. The precipitate was added to $6-\mathrm{cm}$ plates containing $2 \mathrm{ml}$ of fresh medium; the plates were incubated at room temperature for $20 \mathrm{~min}$, and then the medium was brought back up to $5 \mathrm{ml}$, and the plates were placed at $37^{\circ} \mathrm{C}$. Four hours later, the medium was removed, and the plates were (i) covered for $1 \mathrm{~min}$ with $2 \mathrm{ml}$ of fresh medium containing $15 \%$ glycerol, (ii) washed with phosphatebuffered saline, and (iii) fed with $5 \mathrm{ml}$ of fresh medium. Cells were harvested 36 to $48 \mathrm{~h}$ later and assayed for chloramphenicol acetyltransferase activity as described by Gorman et al. (18) and modified by Weeks and Jones (57), except that half of the lysate from a $6-\mathrm{cm}$ plate was incubated with 0.1 $\mathrm{mCi}$ of $\left[{ }^{14} \mathrm{C}\right]$ chloramphenicol (approximately $40 \mathrm{mCi} / \mathrm{mM}$; New England Nuclear Corp., $48 \mu$ l of distilled water, and 1 $\mu l$ of $40 \mathrm{mM}$ acetyl coenzyme A (Sigma Chemical Co.).

\section{RESULTS}

Construction of E1A cDNA genes. CDNAs spanning the introns of the $12 \mathrm{~S}$ and 13S RNAs were isolated from a cDNA library constructed from RNA extracted from Ad2-infected HeLa cells early in infection (15). In each case, the integrity of the splice junctions (41) and protein-coding sequences was confirmed by DNA sequence determination by using the chain termination method (data not shown). E1A genes which individually express only $12 \mathrm{~S}$ and $13 \mathrm{~S}$ RNAs and thus separately express only the 243 - and 289 -amino acid proteins were reconstructed from the appropriate cDNA segments (Fig. 1). Since the 289 -amino acid protein stimulates expression of the viral E1A promoter $(4,36)$, the cDNA genes were placed under the transcriptional control of the mouse metallothionein I promoter (12) to help ensure that the $13 \mathrm{~S}$ and $12 \mathrm{~S}$ cDNA genes would be expressed at similar levels.

No cDNAs spanning the intron of the 9S RNA were obtained, probably because the $9 \mathrm{~S}$ mRNA becomes abundant only at late times after infection. Consequently, an E1A gene was constructed in which the $9 S$ intron had been deleted (Fig. 2). Briefly, endonuclease AvaII cleaves the $12 \mathrm{~S}$ cDNA $18 \mathrm{nt}$ proximal to the 9S donor splice site and $1 \mathrm{nt}$ distal to the 9S splice acceptor (57). Complementary synthetic oligonucleotides with AvaII cohesive ends were synthesized which precisely deleted the intron for the $9 \mathrm{~S}$ mRNA, and an E1A gene colinear with the 9S transcript was reconstructed (MTEB9S).

Figure 3 summarizes the transcription and translation products encoded by the E1A cDNAs and by mutant genomic E1A regions. pHr1 and pHrA contain the E1A region isolated from Ad5 $h r 1$ and $h r 440$ host range mutant viruses. The $h r 1$ mutation deletes $1 \mathrm{nt}$ in the intron of the $12 \mathrm{~S}$ RNA, resulting in the synthesis of a truncated form of the 289-amino acid protein but having no effect on the 243-amino acid protein $(14,44)$. $h r A$ contains two base changes which prevent splicing of the $12 \mathrm{~S}$ mRNA, and consequently the 243-amino acid protein is not made. One of the base changes introduces a termination codon in the reading frame of the $13 \mathrm{~S}$ mRNA, resulting in a truncated polypeptide containing 140 amino acids derived from amino-terminal sequences common to both E1A proteins (50). Finally, dl343 deletes nt 620 and 621 (Hearing, unpublished data). The sequence of $d l 343$ predicts that a frame shift in E1A coding sequences results in the synthesis of a peptide containing 28 amino acids.

Oncogene collaborations. To probe E1A transforming functions, plasmids which separately express the E1A $13 S$

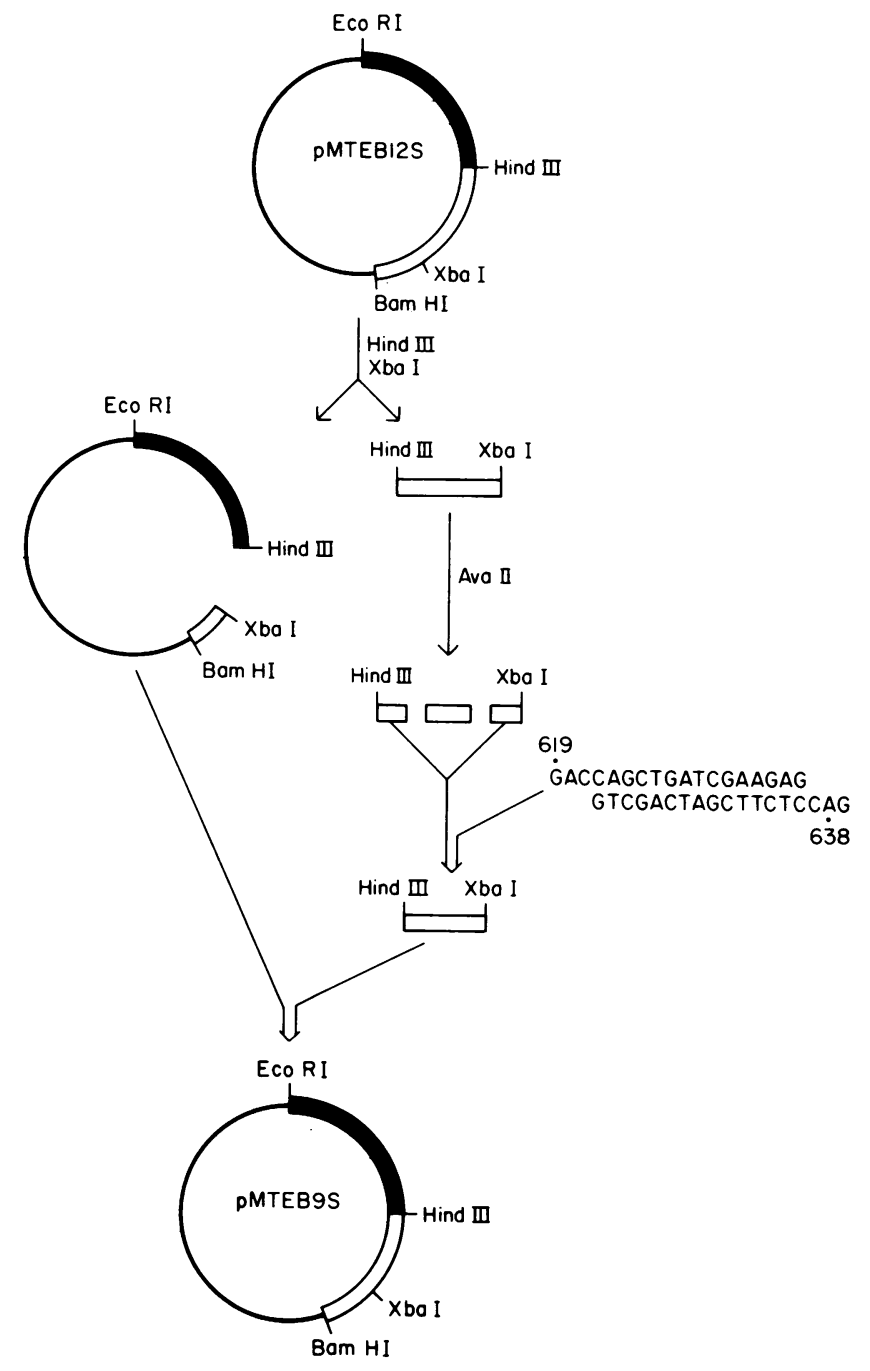

FIG. 2. Construction of E1A 9S cDNA expression plasmid. The smaller HindIII-XbaI fragment of pMTEB12S was digested with Avall, which cut the $12 \mathrm{~S}$ cDNA at nt 618 and at the $9 \mathrm{~S}$ splice acceptor site at nt 1224 . The resulting HindIII-AvaII and AvaII-XbaI fragments were purified and ligated to synthetic complementary oligonucleotides which encompassed the sequence between nt 619 and the $9 \mathrm{~S}$ splice donor site at nt 636 and formed overhanging AvalI cohesive ends when annealed. The resulting 9S cDNA was then cloned into the HindIII-XbaI backbone of pMTEB12S to make pMTEB9S.

(MT13S), 12S (MTEB12S), and 9S (MTEB9S) mRNAs, as well as plasmids carrying mutant E1A regions, were transfected into primary BRK cells alone or together with plasmids containing either pmt or T24 Ha-ras genes. Transfected cultures were monitored for periods of up to 8 weeks for the outgrowth of transformed foci or for clones of cells with extended growth potential.

The results of several experiments are summarized in Table 1. In short, all of the mutant E1A plasmids with the exception of pd1343 and pMTEB9S collaborated with T24 Ha-ras to induce transformed foci. The ability of pHrA to collaborate with T24 Ha-ras suggests that E1A functions important in transformation are located in the aminoterminal domain common to the 289- and 243-amino acid proteins (Fig. 3). That the $12 \mathrm{~S}$ and $13 \mathrm{~S}$ cDNA plasmids were 


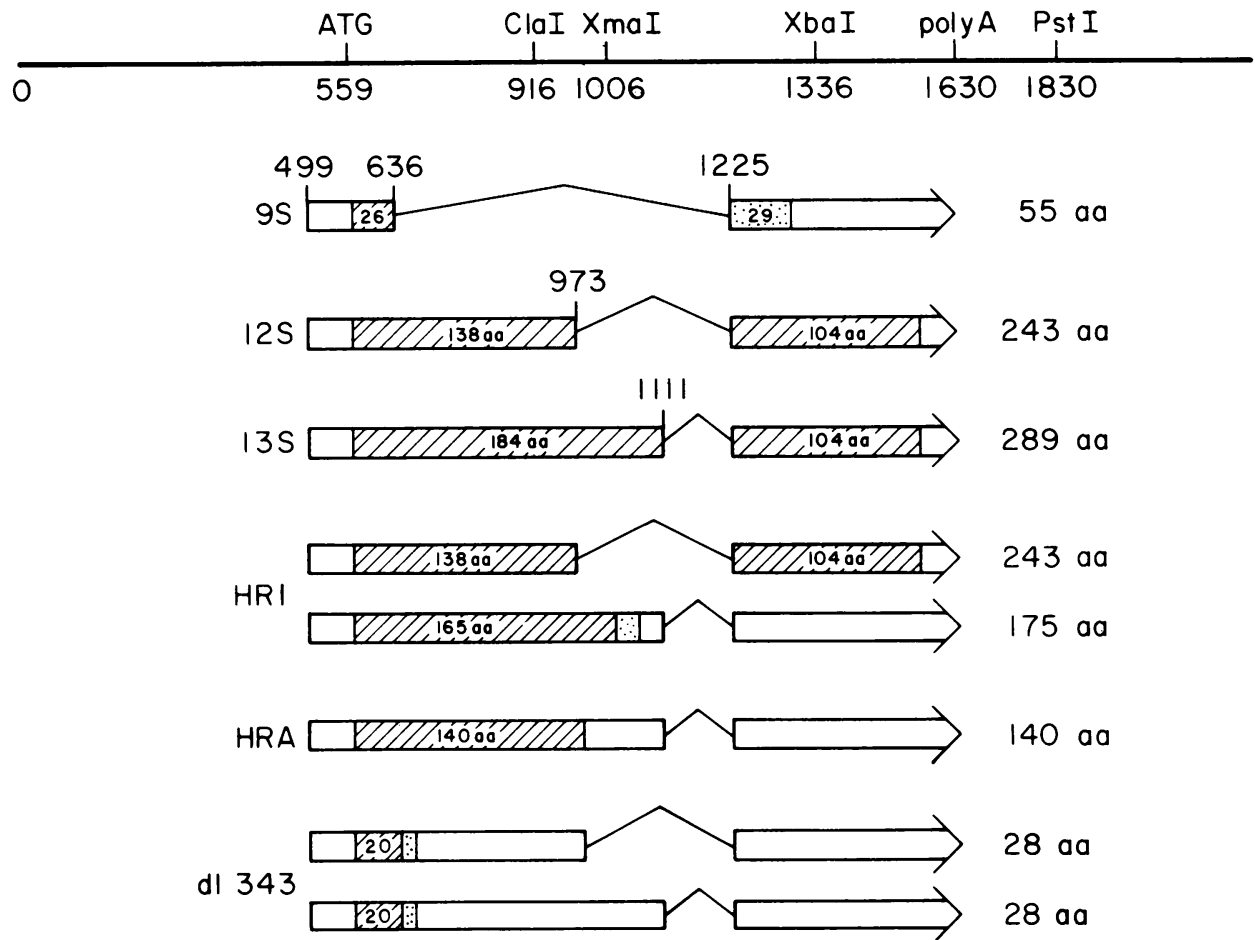

FIG. 3. Adenovirus E1A transcription and translation products. Shown are schematic representations of Adenovirus E1A transcripts ( $\square$ ), the reading frame which encodes the 289- and 243-amino acid E1A proteins ( $\mathbb{Z}$ ), and alternative translational reading frames ( pMTEB9S encodes the E1A 9S mRNA and a 55-amino acid protein; pMTEB12S encodes the E1A 12S mRNA and a 243-amino acid protein; pMT13S encodes the E1A 13S mRNA and a 289-amino acid protein; phrl transcripts are spliced to $12 \mathrm{~S}$ and $13 \mathrm{~S}$ mRNAs which encode the 243-amino acid protein and a truncated polypeptide containing 175 amino acids, of which 10 amino acids are out of frame; pHrA transcripts are spliced to the 13S mRNA, which encodes a truncated polypeptide of 140 amino acids; dl343 synthesizes the $12 \mathrm{~S}$ and $13 \mathrm{~S}$ mRNAs and encodes a truncated polypeptide containing 28 amino acids, of which 8 amino acids are out of frame.

similarly active is consistent with this notion and indicates that the 289- and 243-amino acid proteins express similar activities that are important in the transformation of primary BRK cells. Focus assays after transfection by E1A plasmids alone or together with T24 Ha-ras are shown in Fig. 4. E1A plasmids which complemented T24 Ha-ras were generally also able to collaborate with pmt (Table 1). However, pHrA did not enable pmt to induce transformed foci of primary BRK cells.

As transfected DNA sequences recombine efficiently, the oncogene collaborations might result from sequences on the E1A plasmids (such as an enhancer) which influence the expression of cotransfected genes if brought to a contiguous location by DNA transfection. However, $d l 343$, which contains the adenovirus E1A promoter, and MTEB9S, which contains the metallothionein I promoter, failed to complement T24 Ha-ras. These results indicate that the collaborative functions of E1A resulted from the expression of a protein product and did not result from sequences present on the E1A plasmids.

Cells transformed by E1A and either T24 Ha-ras or pmt plasmids were trypsinized within cloning cylinders, transferred to cloning wells $\left(2 \mathrm{~cm}^{2}\right)$, and consequently expanded to mass culture. DNA was extracted and analyzed by Southern blot hybridization for the presence of sequences homologous to the transfected DNAs. In all cases, the transformed cell lines contained sequences related to the transfected plasmids, and the pattern of hybridizing fragments confirmed the clonal independence of each cell line (data not shown).
Phase-contrast photomicrographs of BRK cells transformed by E1A and T24 Ha-ras or pmt plasmids are shown in Fig. 5. The morphologies of cells transformed by $\mathrm{pHrA}$ and T24 Ha-ras were particularly distinctive. In particular, the cells were epithelial in appearance, a fact which also accounted for distinctive foci produced by pHrA and T24 Ha-ras (Fig. 4). In contrast, cells transformed by other E1A plasmids and T24 Ha-ras were less adherent and more refractile. Reasons for these differences are unknown.

Establishment functions of E1A. The primary explants of BRK cells used in these studies had limited lifespans in serum-containing media. Upon reaching confluence, the cultures rapidly degenerated and became depleted of epithelial cells as a result of cell death and conversion to nonepithelial morphologies. Fibroblast overgrowth was also limited so that after 4 weeks in culture, the cells formed sparse monolayers with few cell-cell contacts. In vitro establishment of BRK cells by pMTE1A, pMT13S, pMTEB12S, and pHr1 was easily demonstrated, since transfecting these plasmids gave rise to morphologically distinct, progressively growing colonies. By contrast, neither T24 Ha-ras nor pmt induced observable alterations in cell growth or morphology.

Microscopic inspection of transfected cultures indicated that the colonies induced by E1A plasmids alone arose within 7 days of transfection. Moreover, colonies arose at frequencies similar to those of the transformants generated by cotransfection of E1A and pmt and only slightly less than those with T24 Ha-ras (Table 1). These results suggest that extended growth potential was a direct response to introduc- 
ing E1A genes and did not require secondary events within the transfected cells.

BRK cells transfected wtih E1A or MT13S plasmids alone have been established, cloned, and maintained with weekly passaging for over 6 months (about 60 cell doublings) without crisis. Initially, cells from growing colonies were trypsinized within cloning cylinders and were plated in cloning wells $\left(2 \mathrm{~cm}^{2}\right)$. However, with few exceptions, cells transferred in this manner failed to thrive. Subsequently established cell populations were isolated as follows: 4 weeks posttransfection, transfected cultures containing 5 to 6 colonies (representing 1,000 to 2,000 cells) were passaged onto culture dishes of similar area. Many of the cells passaged in this manner attached and continued to proliferate. After 4 weeks, the nearly confluent cultures were split 1:2. At this point, the cells had undergone at least 20 doublings, and cells were cloned by limiting dilution and expanded in mass culture. A total of six clones derived from a single transfected plate were analyzed for the presence of E1A sequences by Southern blot hybridization. All contained identical patterns of hybridizing bands (data not shown), indicating that one of the initial colonies outgrew the others as the uncloned cell population was passaged.

pHr1 and pMTEB12S plasmids also induced the outgrowth of cells with extended growth potential. While cells within these colonies grew quickly, passaging the cells, even as mass populations, proved difficult. The cells plated with

TABLE 1. Transformation of primary BRK cells with cloned viral and cellular genes ${ }^{a}$

\begin{tabular}{lcccc}
\hline & \multicolumn{5}{c}{ No. of foci on 4 plates in the following } \\
& \multicolumn{4}{c}{ experiment: } \\
\cline { 2 - 5 } & 1 & 2 & 3 & 4 \\
\hline None (carrier alone) & 0 & 0 & 0 & 0 \\
T24 Ha-ras & 0 & 0 & 0 & 0 \\
PyMT & 0 & 0 & 0 & 0 \\
MTE1A & $(18)$ & $(21)$ & $(14)$ & $(19)$ \\
MT13S & $-{ }^{b}$ & - & $(8)$ & $(5)$ \\
MTEB12S & - & - & $(7)$ & $(10)$ \\
MTEB9S & - & - & 0 & 0 \\
hr1 & $(20)$ & $(16)$ & - & - \\
hrA & 0 & 0 & - & - \\
dl343 & 0 & 0 & - & - \\
MTE1A plus T24 Ha-ras & 57 & 91 & 41 & 68 \\
MTE1A plus PyMT & 9 & 65 & 9 & 11 \\
MT13S plusT24 Ha-ras & - & - & 28 & 34 \\
MT13S plus PyMT & - & - & 4 & 6 \\
MTEB12S plus T24 Ha-ras & - & - & 25 & 22 \\
MTEB12S plus PyMT & - & - & 5 & 8 \\
MTEB9S plus T24 Ha-ras & - & - & 0 & 0 \\
MTEB9S plus PyMT & - & - & 0 & 0 \\
hr1 plus T24 Ha-ras & 61 & 48 & - & - \\
hr1 plus PyMT & 5 & 9 & - & - \\
hrA plus T24 Ha-ras & 32 & 58 & - & - \\
hrA plus PyMT & 0 & 0 & - & - \\
dl343 plus T24 Ha-ras & - & - & 0 & 0 \\
\hline
\end{tabular}

a Plasmids containing viral and cellular genes were transfected by coprecipitation with calcium phosphate. Aliquots $(0.5 \mathrm{ml})$ of DNA-calcium phosphate coprecipitates containing $500 \mathrm{ng}$ of each plasmid and $10 \mu \mathrm{g}$ of rat carrier DNA were added to $60-\mathrm{mm}$ cultures of primary BRK cells. Cells were fixed with methanol-acetone $(1: 1)$ and stained 18 to 56 days posttransfection. Cells transfected with pMTE1A, pMT13S, pMTEB12S, and pHrl did not form dense foci (Fig. 4) but formed colonies of cells having extended growth potential as compared to cells transfected with carrier DNA alone. The number of colonies of this type are indicated in parentheses except when pMTE1A, pMT13S, pMTEB12S, and pHr1 were cotransfected with other plasmids.

b_, Not done. low efficiencies after trypsinization (on the order of 0.1 to $1 \%$ ), and in general, only clumps of cells reattached. We suspect that these difficulties were related to the striking epithelial morphologies of the pMTEB12S- and pHr1transfected cells (Fig. 5) and not to an intrinsic lack of growth potential. Pretreatment of culture vessels with collagen, fibronectin, or poly-L-lysine failed to improve plating efficiencies; however, plating efficiencies gradually improved after repeated passaging. Cells established by $h r 1$ and pMTEB12S have been maintained in culture for over 6 months. This corresponds to at least $\mathbf{4 0}$ doublings, although, given the low plating efficiencies, this figure is certain to be an underestimate.

Transfection of primary BRK cells with pHrA did not generate morphologically distinct colonies of cells (Fig. 5); thus, the ability of $h r \mathrm{~A}$ to promote primary cell establishment was more difficult to demonstrate. However, by passaging transfected cultures, it was possible to isolate populations of established cells essentially as before, although an additional passaging step was required. Thus, transfected cultures were passaged 4 weeks posttransfection onto culture dishes of similar area. After 4 weeks, the cultures contained two to five growing colonies, which were passaged again onto culture dishes of similar area. After 3 weeks, confluent cultures were split 1:2 and were subsequently subcloned by limiting dilution. DNAs from six clones were analyzed by Southern blot hybridization, and E1A sequences were present as single inserts of similar size in two clones, suggesting that both were sibling clones (data not shown).

Phase-contrast photomicrographs of BRK cells established by pMTE1A, pMT13S, pMTEB12S, pHr1, and pHrA are shown in Fig. 5. All exhibited properties expected of nontransformed established cell lines. In particular, the cells displayed high serum requirements for growth, grew to low saturation densities, and failed to form tumors in syngeneic rats after subcutaneous injection of $10^{6}$ cells.

In repeated experiments in addition to those listed in Table 1, the T24 Ha-ras, pmt, MTEB9S, and E1A mutant dl343, individually and in combinations, failed to induce observable alterations in the growth or morphology of primary BRK cells. Failure of the T24 Ha-ras gene to transform was confirmed in attempts to detect cellular genes in DNA from human tumor cells which might enable T24 Ha-ras to transform primary BRK cells. In particular, DNA extracted from six tumor cell lines when cotransfected with T24 Ha-ras gave rise to four untransformed colonies on 600 dishes of primary BRK cells. However, cells derived from these colonies required months to establish and contained neither human Alu repeat sequence DNA nor sequences related to the T24 Ha-ras plasmid, as judged by Southern blot analysis. One assumes, therefore, that these clones represented rare, spontaneously established variants.

Transforming functions of E1A plasmids. The ability of plasmids to facilitate establishment in vitro and to collaborate with T24 Ha-ras or polyomavirus middle $\mathrm{T}$ in transformation is summarized in Table 2 . Briefly, with the exception of $\mathrm{pHrA}$, all plasmids which individually facilitated establishment of primary BRK cells also collaborated with T24 $\mathrm{Ha}-$ ras and polyomavirus middle $\mathrm{T}$ in transformation. ( $\mathrm{pHrA}$ cooperated with T24 Ha-ras in transformation but not with polyomavirus middle $\mathrm{T}$ ). These results indicate that activities which enable T24 Ha-ras and polyomavirus middle T to transform cultured primary BRK cells are tightly linked to activities which facilitate in vitro establishment.

In other experiments, we assessed the ability of T24 


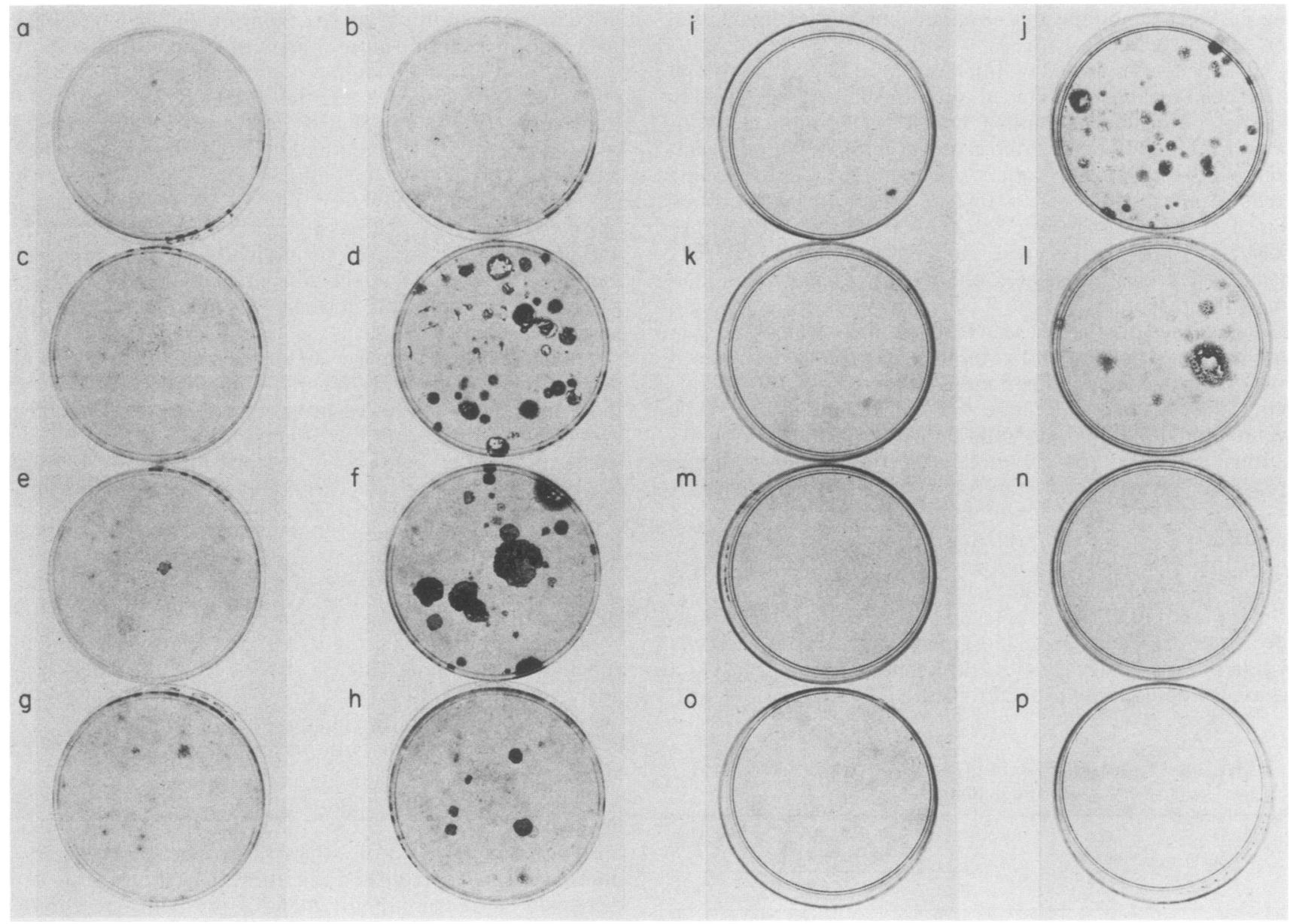

FIG. 4. Focus assay after transfection of BRK cells by E1A plasmids alone or together with T24 Ha-ras. Cells were transfected with cloned genes, fixed, and stained as described in the legend to Table 1 . Transfected cultures were stained after 8 weeks except those on plates $\mathrm{d}, \mathrm{f}, \mathrm{h}, \mathrm{j}$, and $\mathrm{l}$, which were stained after 18 days. Plates: a, no plasmid (carrier alone); b, T24 Ha-ras; c, MTE1A; d, MTE1A plus T24 Ha-ras; e, pHrA; f, pHrA plus T24 Ha-ras; g, pHr1; h, pHr1 plus T24 Ha-ras; i, MT13S; j, MT13S plus T24 Ha-ras; k, MTEB12S; 1 , MTEB12S plus T24 Ha-ras; m, MTEB9S; n, MTEB9S plus T24 Ha-ras; o, dl343; p, dl343 plus T24 Ha-ras.

Ha-ras cotransformants to form progressively growing tumors in 14-day-old syngeneic rats after subcutaneous injection of $10^{6}$ cells (Table 2). However, no consistent pattern emerged with regard to other transformation parameters, namely, tumorigenicity of T24 Ha-ras cotransformants or ability to collaborate with polyomavirus middle $T$. Thus, $\mathrm{pHrA}$ failed to collaborate with polyomavirus middle $\mathrm{T}$, but $h r \mathrm{~A} / \mathrm{T} 24 \mathrm{Ha}$-ras cotransformants were tumorigenic in syngeneic rats. On the other hand, $\mathrm{pHrl}$ collaborated with polyomavirus middle $\mathrm{T}$, but $h r 1 / \mathrm{T} 24 \mathrm{Ha}$-ras cotransformants were not tumorigenic.

E1A gene expression and detection of E1A mutant transcripts. RNA was extracted from cells transformed by T24 Ha-ras and MTE1A, MT13S, or MTEB12S. E1A related transcripts were analyzed after hybridization to probes generated in vitro with SP6 polymerase. Cells transformed by MTE1A and either T24 Ha-ras or polyomavirus middle T expressed both $12 \mathrm{~S}$ and 13S E1A mRNAs, whereas cells transformed with E1A cDNA plasmids (pMT13S or pMTEB12S) expressed only the appropriate E1A mRNA (Fig. 6A).

In a similar analysis performed on cells transformed by T24 Ha-ras and either $h r A$ or $h r 1$, SP6 probes generated from wild-type Ad5 E1A (Fig. 6B) were used initially. As
HrA is unable to splice $12 \mathrm{~S}$ RNA, we had expected fragments of 299 and 117 nt derived from the 5' and 3' exons of the $13 S$ transcript to be protected. Instead, the Ad5 E1A SP6 probe protected fragments of approximately 165 and $117 \mathrm{nt}$ (Fig. 6B, lane 3), similar in size to fragments diagnostic of the $12 \mathrm{~S}$ transcript (Fig. 6B, lane 7). In addition, a 137-nt fragment was generated. This result suggested that hybrids formed between the wild-type Ad5 E1A probe and Ad5 $\mathrm{hrA}$ 13S RNA were cleaved internally near the $12 \mathrm{~S}$ splice donor due to mismatched base pairs resulting from the $h r A$ lesion. This possibility was confirmed by using an SP6 probe generated from $h r A$ E1A sequences. The $h r A$ probe protected fragments diagnostic of $13 \mathrm{~S}$ transcripts, confirming that $h r \mathrm{~A} / \mathrm{T} 24$ transformants express only the 13S E1A (Fig. $6 \mathrm{~B}$, lane 5).

Likewise, hybrids formed between Ad5 hr1 RNA and wild-type Ad5 E1A probe were partially cleaved at the site of the $h r 1$ lesion (Fig. 6B, lane 4). This was indicated by the appearance of a protected fragment $241 \mathrm{nt}$ in size derived from cleavage of the 299-nt fragment. However, an SP6 probe generated from $h r l$ sequences protected the expected fragments characteristic of $13 \mathrm{~S}$ and $12 \mathrm{~S}$ transcripts (Fig. 6B, lane 6).

It should be noted that pMTEB12S and pMT13S were 

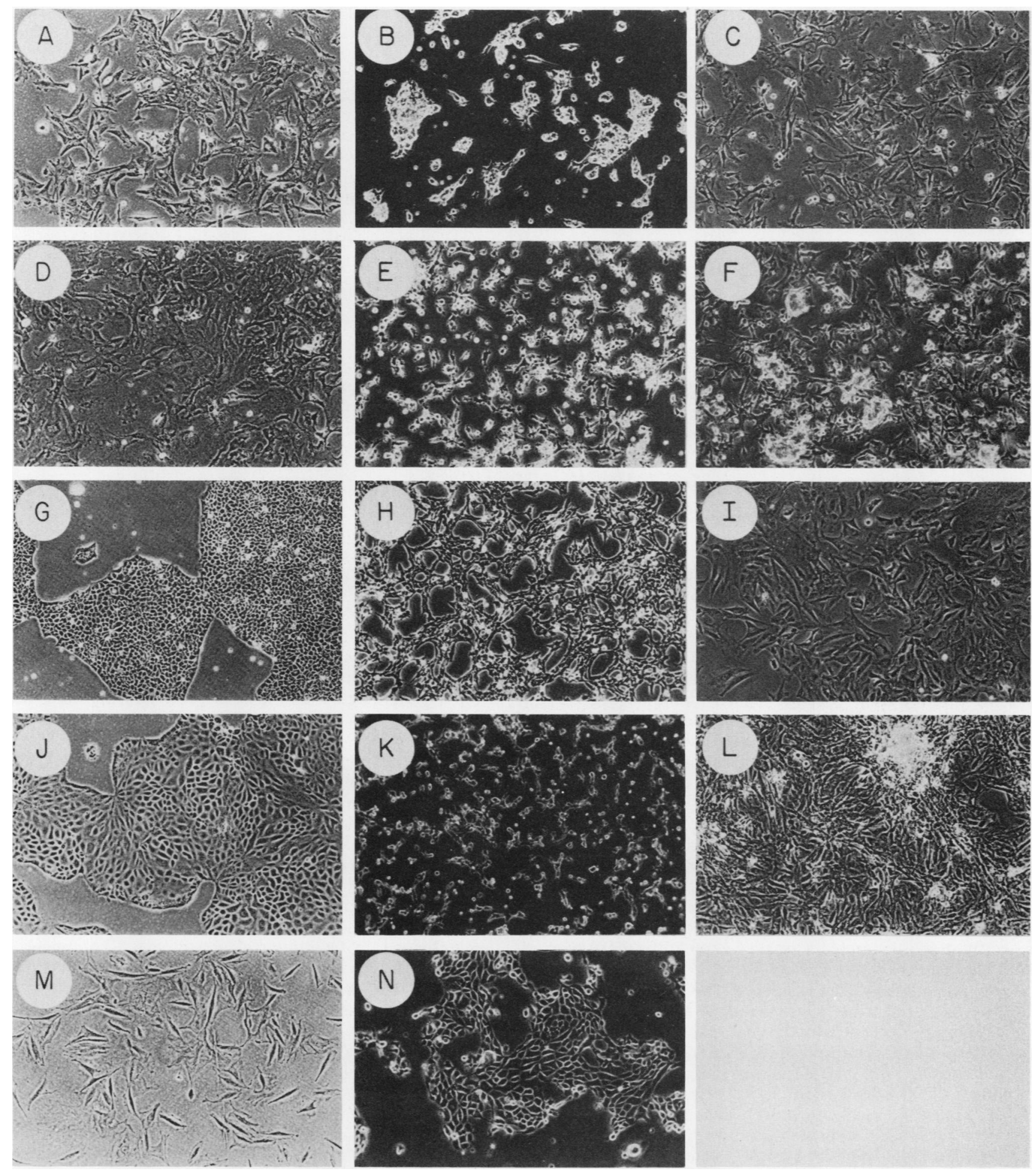

FIG. 5. Established and transformed BRK cell clones. Primary BRK cells were established by transfecting E1A plasmids alone or were transformed by cotransfecting E1A and either T24 Ha-ras or polyomavirus middle T plasmids. (A) pMTE1A (clone MT1A-1); (B) pMTE1A plus T24 Ha-ras (clone MT1AR-1); (C) pMTE1A plus polyomavirus middle T (clone MT1AMT-1); (D) pMT13S (clone 13S-1); (E) MT13S plus T24 Ha-ras (clone 13SR-2); (F) MT13S plus polyomavirus middle T (clone 13SMT-1); (G) MTEB12S (clone 12S-1); (H) MTEB12S plus T24 Ha-ras (clone 12SR-1); (I) MTEB12S plus polyomavirus middle T (clone 12S MTI); (J) pHr1 (clone Hr1-1); K, pHr1 plus T24 Ha-ras (clone 9-3-1); (L) pHr1 plus polyomavirus middle T (clone Hr1 MT-2); (M) pHrA (clone HrA-2); (N) pHrA plus T24 Ha-ras (clone 28-3-1). Clones derived from transformed foci (panels B, C, E, F, H, I, K, L, and N) were photographed after approximately 30 cell doublings. Established clones derived after transfection of E1A plasmids alone (panels A, D, G, J, and M) were photographed after subcloning from serially passaged mass cultures (see the text) after an estimated 40 to 60 cell doublings. All photomicrographs were taken with a $10 \times$ objective. Prints were all made at identical magnifications. 
TABLE 2. Transforming functions of E1A plasmids

\begin{tabular}{lcccc}
\hline Plasmid & $\begin{array}{c}\text { Facilitation } \\
\text { of establish- } \\
\text { ment }\end{array}$ & $\begin{array}{c}\text { Collaboration } \\
\text { with T24 } \\
\text { Ha-ras }\end{array}$ & $\begin{array}{c}\text { Production of } \\
\text { tumorigenic } \\
\text { ras cotrans- } \\
\text { formants }\end{array}$ & $\begin{array}{c}\text { Collaboration } \\
\text { with polyoma- } \\
\text { virus middle }\end{array}$ \\
\hline pMTE1A & + & + & + & + \\
pMT13S & + & + & + & + \\
pMTEB12S & + & + & + & + \\
pMTEB9S & - & - & - & - \\
pHr1 & + & + & + & + \\
pHrA & $+b$ & + & & - \\
pd1343 & - & - & & - \\
\hline
\end{tabular}

a Plasmids expressing wild-type and mutant adenovirus E1A transcription units were introduced into BRK cells individually and together with plasmids expressing the T24 Ha-ras and polyomavirus middle $\mathrm{T}$ antigen genes. The ability $(+)$ or inability $(-)$ of E1A plasmids to facilitate establishment of primary BRK cells and to collaborate with T24 Ha-ras and polyomavirus middle $T$ antigen to induce transformed foci is indicated. Transformants generated after cotransfection of E1A plasmids and T24 Ha-ras were tested for tumorigenicity in 14-day-old syngeneic rats after subcutaneous injection of $10^{6}$ cells. Three transformed lines generated with each E1A plasmid were injected into four animals each. All E1A-ras cotransformants (except hrl-ras cotransformants) gave rise (within 4 weeks) to progressively growing tumors in at least two of the injected animals, whereas none of the three hrl-rastransformed lines induced tumors after 12 weeks.

${ }^{b}$ Establishment activities of $\mathrm{pHrA}$ were low as compared with those of other E1A plasmids.

constructed with Ad2 cDNA sequences inserted into Ad5 E1A genes. Ad2 mRNA sequences are identical to swapped Ad5 sequences except at nt 1287, 1297, and 1301. Cleavage at these positions would generate multiple fragments derived from the 117-nt fragment. It was not clear whether single mismatched bases were cleaved under the conditions used in this study. Nevertheless, the $h r A$ mutation, consisting of two adjacent base changes, and the $h r 1$ mutation, consisting of a single-nucleotide deletion, were both detected by RNase protection analysis. We are presently investigating whether mutations resulting from single-base changes can be detected by this method.

The presence of the expected viral mRNA in cells established by E1A, E1A cDNAs, and pHrA was confirmed by analysis of the in vitro translation products of E1A hybrid selected RNA (Fig. 7). Hybrid-selected RNA isolated from cells established by MT13S and MTEB12S generated translation products corresponding to the 289- and 243-amino acid E1A proteins, respectively. RNA selected from cells established by pHrA generated a smaller peptide band estimated at $\mathbf{4 0}$ kilodaltons.

Gene activation by E1A products. The role of individual E1A proteins regarding transcriptional activation of viral early region promoters is not completely resolved. On one hand, viruses expressing only the $13 \mathrm{~S}$ E1A RNA replicate as efficiently as do wild-type viruses in HeLa cells (25, 36, 60; B. Moran, T. Grodzicker, R. J. Roberts, M. B. Mathews, and B. Zerler, J. Virol., in press), indicating that the 289amino acid protein is sufficient for transcriptional activation. Moreover, mutants defective in the 289 -amino acid protein, such as Ad5 $h r 1$, are defective for transcriptional activation (4). On the other hand, several mutants defective in the 289-amino acid protein, such as Ad5 in500 (8) and Ad5 hr440 ( $h r A)(51)$ retain partial transcription-activating functions. In addition, conflicting results have been reported concerning trans activation of early region promoters by cotransfected E1A plasmids $(34,53)$.

In view of this somewhat contradictory literature, transcriptional activation by E1A plasmids was assessed by a transient assay system (58). This assay exploits the fact that the bacterial chloramphenicol acetyltransferase gene under transcriptional control of the adenovirus E3 promoter depends on E1A for efficient expression.

Only those plasmids which encoded the 289-amino acid E1A protein stimulated expression of E3CAT (Fig. 8; Table 3). Thus, pMTEB12S, pMTEB9S, pHr1, and pHrA failed to stimulate E3CAT expression. Similar results were also obtained with plasmids containing E1A, E1A13S, E1A12S, and E1A9S genes expressed from the viral E1A promoter (Moran et al. submitted). Moreover, we have reconstructed mutant adenoviruses which separately express E1A transcripts colinear with the $13 \mathrm{~S}, 12 \mathrm{~S}$, and $9 \mathrm{~S}$ cDNAs, and only the $13 \mathrm{~S}$ virus exhibited any E1A transcription-activating functions (Moran et al., J. Virol., in press).

Together, the results of these experiments support previously published studies that the 289 -amino acid protein is responsible for most, if not all, E1A transcription-activating functions. Since pMTEB12S, pHr1, and HrA collaborate with T24 Ha-ras and facilitate in vitro establishment, we conclude that neither of these activities is linked to E1A functions required for efficient transcriptional activation of viral early region promoters.

\section{DISCUSSION}

Neither T24 Ha-ras nor pmt induced observable alterations in the growth or morphology of primary BRK cells. By contrast, both genes induced phenotypes associated with oncogenic transformation when cotransfected with E1A plasmids capable of facilitating in vitro establishment. Thus, E1A activities which enable ras and pmt genes to transform primary BRK cells appear to be linked to E1A functions which facilitate in vitro establishment. Furthermore, both E1A activities were expressed by sequences encoding a protein containing 140 amino acids, derived from the aminoterminal domain shared by the E1A 289- and 243-amino acid proteins. These results provide further evidence that oncogenic transformation can require complementing activities which separately enable cultured cells to escape senescence and acquire tumorigenic phenotypes.

The biochemical basis for the establishment and transforming steps and how these collaborate is presently unknown. While E1A increases the proliferative potential of primary BRK cells and facilitates in vitro establishment, serum growth factors, T24 Ha-ras, and pmt fail to alter cellular commitments towards growth arrest and senescence. Indeed, by facilitating establishment, E1A appears to enable BRK cells to respond to activities of serum growth factors and ras and pmt oncogenes.

Several observations suggest that in vitro establishment is not an obligatory consequence of extended proliferative potential. (i) Cells from progressively growing colonies induced by E1A initially failed to grow when plated at low cell densities. (ii) Cells from individual clones rapidly overgrew mass cultures established from several E1A-induced colonies. (iii) The plating efficiencies of cells established by $\mathrm{pHr} 1$ and $12 \mathrm{~S}$ cDNA plasmids improved gradually as a result of successive passages. Thus, in vitro establishment and the ability to grow indefinitely in serum-containing media probably require adapative changes in addition to extended growth potential induced by E1A.

Transfected pHrA did not clearly induce morphologically altered colonies of BRK cells. Therefore, the ability of $\mathrm{pHrA}$ to alter the growth potential of BRK cells was more difficult to establish as compared with other E1A plasmids. However, since spontaneous establishment and DNA uptake after transfection are both rare events, it seems unlikely that 


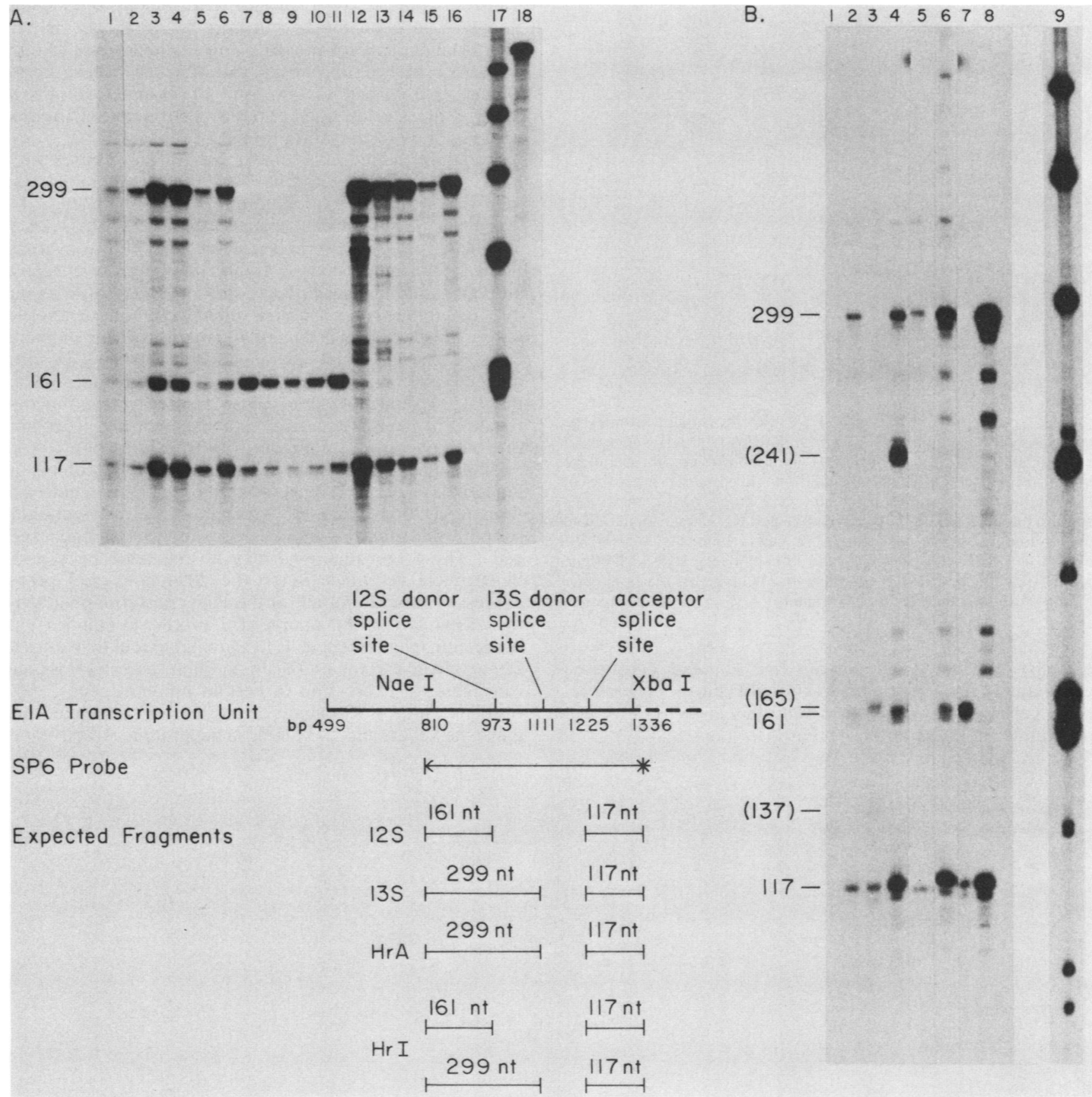

FIG. 6. E1A transcripts in transformed BRK clones. RNA from BRK cell clones was annealed to ${ }^{32}$ P-labeled RNA probes generated in vitro by SP6 polymerase. Fragments resistant to RNase digestion were analyzed by polyacrylamide gel electrophoresis and autoradiography. RNA probes complementary to E1A transcripts were expected to protect fragments of 299 and $117 \mathrm{nt}$ and 161 and $117 \mathrm{nt}$ derived from $13 \mathrm{~S}$ and $12 \mathrm{~S}$ transcripts, respectively. Sequences corresponding to SP6 probes and also fragments expected to be protected by RNA from E1A mutant and cDNA genes are indicated schematically. (A) RNA isolated from the following BRK cell clones was annealed to Ad5 SP6 probes and analyzed as described above: clone MT1A1 (lane 1), established by pMTE1A; clone MT1AR-1 (lane 2); clones MT1AR-2 (lane 3) and MT1AR-3 (lane 4), transformed by pMTE1A and pT24; clones MT1AMT-1 (lane 5) and MT1AMT-2 (lane 6), transformed by pMTE1A and pPyMT; 12SR-1 (lane 7), 12SR-2 (lane 8), and 12SR-3 (lane 9), transformed by pMTEB12S and pT24; 12S MT-1 (lane 10) and 12S MT-2 (lane 11), transformed by pMTEB12S and pPyMT; 13SR-1 (lane 12), 13SR-2 (lane 13), 13SR-3 (lane 14), and 13SR-4 (lane 15), transformed by pMT13S and pT24; 13SMT-1 (lane 16), transformed by pMT13S and pPyMT. Lane 17, Size markers derived from end-labeled HinfI-digested pAT153 DNA; lane 18, Ad5 SP6 probe. (B) RNA extracted from BRK cell lines was annealed to the indicated SP6 probes and analyzed as described above: primary BRK cell, Ad5 probe (lane 1); (2) MT1AMT-1 transformed by pMTE1A and pPyMT, Ad5 probe (lane 2); 9-3-1 transformed by pHrl and pT24, Ad5 probe (lane 3); 28-3-1 transformed by pHrA and pT24, Ad5 probe (lane 4); 9-3-1, Ad5 hrl probe (lane 5); 28-3-1, Ad5 hrA probe (lane 6); 12SR-1 transformed by pMTEB12S and pT24, Ad5 probe (lane 7); 13SR-3 transformed by pMT13S and pT24, Ad5 probe (lane 8). Lane 9, Size markers derived from end-labeled, Hinfl-digested pAT153 DNA. 


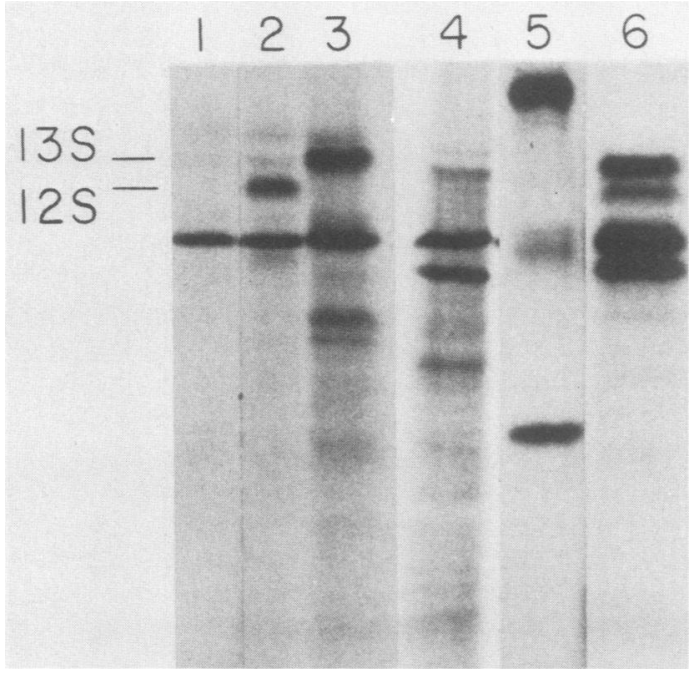

FIG. 7. In vitro translation of E1A mRNAs isolated from E1Aestablished BRK cell lines. Cytoplasmic RNA $(200 \mu \mathrm{g})$ was hybridized to an E1A plasmid (pHEB4) immobilized on nitrocellulose filters. Eluted RNA was translated in vitro in the presence of $\left[{ }^{35}\right.$ S]methionine, and the products were fractionated on a $15 \%$ sodium dodecyl sulfate-polyacrylamide gel. RNA was isolated from the following cells: primary BRK cells (lane 1), MTEB12S established BRK cells (lane 2), MT13S-established BRK cells (lane 3), HrA-established BRK cells (lane 4), ${ }^{14}$-C labelled markers (lane 5), and Ad2-infected HeLa cells (lane 6).

established cells would contain and express transfected genes unless these participated in establishment. Therefore, pHrA appears to facilitate establishment at a low, but detectable, frequency.
pHrA also failed to complement pmt in primary cell transformation. In this respect, $h r A$ resembles plt, since plt also fails to collaborate with pmt but facilitates in vitro establishment and collaborates with ras oncogenes to transform rat embryo fibroblasts $(33,42,43)$. These results indicate that certain combinations of plasmids which separately express establishment and transforming functions do not cooperate to transform primary cells.

Studies with Ad5 $h r 440(h r A)$ and $h r 1$ and viruses which individually express only the 243- and 289-amino acid proteins have shown that all are defective with regard to transformation of cultured primary cells $(2,19,22,23,25,37$, 51, 60; Moran et al., in press). However, viral transformation may be influenced by transcriptional effects such as autoregulation of E1A or activation of E1B as well as viral cytotoxicity in semipermissive rodent cells. These considerations greatly complicate understanding of the individual roles of the 243- and 289-amino acid proteins in virusinduced cell transformation. The present study indicates that the E1A regions of all of these viruses retain functions required to facilitate in vitro establishment and to collaborate with oncogenes in primary cell transformation.

While the biochemical functions of E1A proteins are unknown, E1A expresses at least two functions required for virus replication. Thus, E1A activates viral early gene transcription and greatly stimulates virus replication in quiescent cells. These two functions may be mediated by separate biochemical activities, since the 289 -amino acid protein expresses most, if not all, of the E1A transcriptional activities, whereas the 243 -amino acid protein stimulates virus replication in quiescent cells to a greater extent than does the 289-amino acid protein (37). In addition, both E1A proteins can influence expression of certain nonviral genes, either resident within the genome or carried on transfected plasmids; however, the 243 -amino acid protein is active only

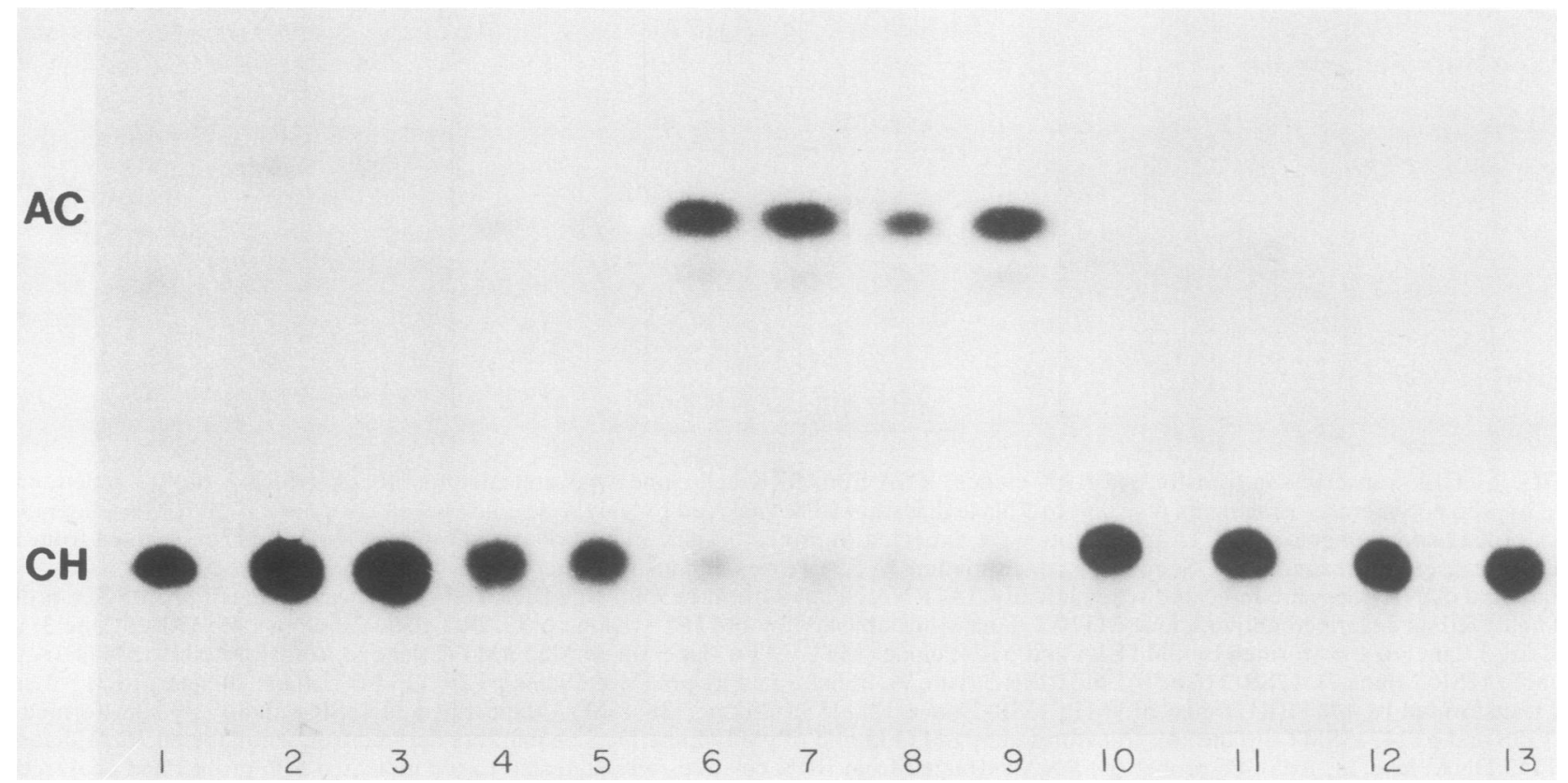

FIG. 8. Transcriptional activation by E1A plasmids. A 5- $\mu$ g sample of the indicated plasmid DNA, along with $5 \mu \mathrm{g}$ of pKCAT23 and 10 $\mu \mathrm{g}$ of carrier DNA, was transfected into HeLa cells by calcium phosphate coprecipitation. After $48 \mathrm{~h}$, cells were harvested, and extracts were assayed for chloramphenicol acetyltransferase activity. Lanes: 1, pKCAT23 alone; 2 and 3, MTEB9S plus pKCAT23; 4 and 5, pMTEB12S plus pKCAT23; 6 and 7, pMT13S plus pKCAT23; 8 and 9, pMTE1A plus pKCAT23; 10 and 11, pHrA plus pKCAT23; 12 and 13, pHr1 plus pKCAT23. Acetylated $(\mathrm{AC})$ and unacetylated $(\mathrm{CH})$ forms of chloramphenicol are indicated. 
TABLE 3. Transcriptional activation by E1A plasmids

\begin{tabular}{|c|c|}
\hline Plasmid & $\begin{array}{l}\% \text { Chloramphenicol } \\
\text { acetylated per } \mathrm{h}^{a}\end{array}$ \\
\hline pMTE1A & $69 \pm 11$ \\
\hline pMT13S .... & $82 \pm 3$ \\
\hline pMTEB12S. & $9.1 \pm 0.1$ \\
\hline 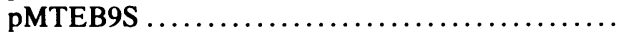 & $6.6 \pm 1.2$ \\
\hline pHr1...... & $2.2 \pm 0.8$ \\
\hline pHrA ...... & $11.3 \pm 2.6$ \\
\hline 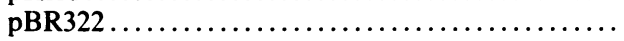 & $7.4 \pm 0.8$ \\
\hline
\end{tabular}

a Plasmid DNAs were cotransfected with pKCAT23 which contains the bacterial chloramphenicol acetyltransferase gene expressed from the adenovirus E3 promoter. Acetylation of chloramphenicol was monitored after thin-layer chromatography and is expressed as percent chloramphenicol acetylated per hour. Mean and standard deviation of at least two experiments are given.

with a subset of genes affected by the 289 -amino acid protein $(34,47,53,56)$. Finally, both E1A proteins stimulate cellular DNA synthesis during lytic infection $(3,52)$; however, only the 289-amino acid protein induces cell cycle progression (3).

The relationship of these biological activities to transformation is presently unknown, but the activities implicate transcription and DNA replication as targets of E1A functions. Transcriptional effects of E1A are particularly interesting since associations between transcriptional activation and transformation have been noted for proteins other than E1A $(6,10,31,32,49)$. Unfortunately, experimental evidence linking transcriptional effects and transformation is inconclusive. On one hand, the present study indicates that E1A functions which facilitate establishment are separate from activities of the 289 -amino acid protein which activate transcription of the viral early region genes. On the other hand, transcription and transformation phenotypes could result from different thresholds of a single activity rather than from separate biochemical activities. Moreover, viral and cellular genes may differ in their responses to E1A. In either event, since E1A activities which induce cultured primary cells to proliferate must also alter cellular gene expression, distinguishing cause and effect will be a difficult undertaking.

Understanding how E1A transcriptional effect influences transformation is further complicated by the fact that many transcriptional phenotypes associated with E1A appear to be indirect. The wide variety of transcriptional phenotypes associated with E1A suggests that E1A can influence transcription at many different levels. Kinetics of transcriptional activation suggests that E1A acts in collaboration with other cellular proteins to alter transcription units in cis (16). Moreover, E1A proteins may not interact directly with promoter elements, since sequences necessary for gene expression in the presence of E1A vary for different promoters $(21,27,54)$. Finally, a variety of factors, including inhibitors of protein synthesis $(38,48)$, cell differentiation (26), and tumor promoters (9), all influence transcriptional phenotypes associated with E1A.

Several investigators $(36,52)$ have proposed that E1A activities which stimulate adenovirus replication in quiescent cells participate directly in primary cell transformation. If this hypothesis is correct, quantitative rather than qualitative differences would appear to distinguish the 243- and 289-amino-acid proteins with regard to activities necessary for the efficient infection of quiescent cells, since the 289and 243-amino acid proteins express similar transforming functions. While it is not clear how E1A transforming activities participate in virus replication, these activities presumably help create or maintain cellular environments permissive for viral DNA replication. It is interesting that phenotypes induced by E1A are also induced by cellular genes, including certain oncogenes activated in tumor cells $(13,28,33,40)$. E1A may therefore activate or express activities similar to these oncogene proteins.

While the biochemical functions of the E1A proteins are unknown, E1A alters the ability of BRK cells to respond to activities of T24 Ha-ras p21 and pmt as well as to activities induced by serum growth factors. The requirement for collaborations between oncogenes to transform primary BRK cells has allowed the transforming functions of E1A proteins to be more accurately defined. This system, as well as others in which cellular responses to serum growth factors and to certain oncogene proteins are conditional on coexpression of genes such as E1A, may allow complementing biochemical activities involved in oncogenic transformation to be identified. This will assist efforts to understand the biochemical functions of E1A and mechanisms which regulate how cells synthesize and respond to signals involved in cellular growth control.

\section{ACKNOWLEDGMENTS}

We thank Mike Mathews and Rich Roberts for many helpful discussions, David Solnick and Patrick Hearing for providing plasmids, and Eileen Feldman for help preparing this manuscript.

This work was supported by grants from the Whitaker Health Sciences Fund and the Rita Allen Foundation and by Public Health Service grant CA13106 from the National Cancer Institute. K.M. was supported by the Robertson Research Fund.

\section{LITERATURE CITED}

1. Allan, M., J.-D. Zhu, P. Montague, and J. Paul. 1984. Differential response of multiple $\epsilon$-globin cap sites to cis and trans-acting controls. Cell 38:399-407.

2. Babiss, L. E., H. S. Ginsberg, and P. B. Fisher. 1983. Cold sensitive expression of transformation by a host range mutant of type 5 adenovirus. Proc. Natl. Acad. Sci. USA 80:1352-1356.

3. Bellett, A. J. D., P. Li, E. T. David, E. J. Mackey, A. W. Braithwaite, and J. R. Cutt. 1985. Control functions of adenovirus transformation region E1A gene products in rat and human cells. Mol. Cell. Biol. 5:1933-1939.

4. Berk, A. J., F. Lee, T. Harrison, J. Williams, and P. A. Sharp. 1979. Pre-early adenovirus 5 gene product regulates synthesis of early viral messenger RNAs. Cell 17:935-944.

5. Borelli, E., R. Hen, and P. Chambon. 1984. Adenovirus-2 E1A products repress enhancer-induced stimulation of transcription. Nature (London) 312:608-612.

6. Brady, J., and G. Khoury. 1985. trans activation of the simian virus 40 late transcription unit by $\mathrm{T}$-antigen. Mol. Cell. Biol. 5:1391-1399.

7. Capon, D. J., E. J. Chen, A. D. Levinson, P. H. Seeberg, and D. V. Goeddel. 1983. Complete nucleotide sequences of the T24 human bladder carcinoma oncogene and its normal homologue. Nature (London) 302:33-37.

8. Carlock, L. R., and N. C. Jones. 1981. Transformation-defective mutant of adenovirus type 5 containing a single altered Ela mRNA species. J. Virol. 40:657-664.

9. Carter, T. H., Z. Z. Milovanovic, L. E. Babiss, and P. B. Fisher. 1984. Accelerated onset of viral transcription in adenovirusinfected HeLa cells treated with tumor promoter 12-Otetradecanoyl-phorbol-13-acetate. Mol. Cell. Biol. 4:563-566.

10. Chen, I. S., D. J. Slamon, J. D. Rosenblatt, N. P. Shah, S. G. Quan, and W. Wachsman. 1985. The $x$ gene is essential for HTLV replication. Science 229:54-58.

11. Chirgwin, J. M., A. E. Przybyla, R. J. MacDonald, and W. J. Rutter. 1979. Isolation of biologically active ribonuclease acid from sources enriched in ribonuclease. Biochemistry 18:5294 5299.

12. Durnam, D. M., F. D. Perrin, F. Gannon, and R. D. 
Palmiter.1980. Isolation and characterization of the mouse metallothionein I gene. Proc. Natl. Acad. Sci. USA 77:6511-6516.

13. Eliyahu, D., A. Raz, P. Gruss, D. Givol, and M. Oren. 1984. Participation of p53 cellular tumor antigen in transformation of normal embryonic cells. Nature (London) 312:646-649.

14. Esche, H., M. B. Mathews, and J. B. Lewis. 1980. Proteins and messenger RNAs of the transforming region of wild-type and mutant adenoviruses. J. Mol. Biol. 142:399-417.

15. Freyer, G. A., Y. Katoh, and R. J. Roberts. 1984. Characterization of the major mRNAs from adenovirus 2 early region 4 by cDNA cloning and sequencing. Nucleic Acids Res. 12:35033519.

16. Gaynor, R. B., and A. J. Berk. 1983. Cis-acting induction of adenovirus transcription. Cell 33:683-693.

17. Goldfarb, M., K. Shimizu, M. Perucho, and M. Wigler. 1982. Isolation and preliminary characterization of a human transforming gene from T24 bladder carcinoma cells. Nature (London) 296:404-409.

18. Gorman, C. M., L. F. Moffat, and B. H. Howard. 1982. Recombinant genomes which express chloramphenicol acetyltransferase in mammalian cells. Mol. Cell. Biol. 2:1044-1051.

19. Graham, F. L., T. Harrison, and J. Williams. 1978. Defective transforming capacity of adenovirus type 5 host range mutants. Virology 86:10-21.

20. Graham, F. L., and A. J. van der Eb. 1973. A new technique for the assay of the infectivity of adenovirus 5 DNA. Virology 52:456-467.

21. Green, M. R., R. Triesman, and T. Maniatis. 1983. Transcriptional activation of cloned human Beta globin genes by viral immediate early gene products. Cell 35:137-148.

22. Haley, K. P., J. Overhauser, L. E. Babiss, H. S. Ginsberg, and N. C. Jones. 1985. Transformation properties of type 5 adenovirus mutants that differentially express the E1A gene products. Proc. Natl. Acad. Sci. USA 81:5734-5738.

23. Ho, Y.-S., R. Galos, and J. Williams. 1982. Isolation of type 5 adenovirus mutants with a cold-sensitive host range phenotype: genetic evidence of an adenovirus transformation maintenance function. Virology 122:109-124.

24. Houweling, A., P. J. van der Elsen, and A. J. van den Eb. 1980. Partial transformation of primary rat cells by the leftmost $4.5 \%$ fragment of adenovirus 5 DNA. Virology 105:537-550.

25. Hurwitz, D. R., and G. Chinnadurai. 1985. Evidence that a second tumor antigen coded by adenovirus early gene region Ela is required for efficient cell transformation. Proc. Natl. Acad. Sci. USA 82:163-167.

26. Imperiale, M. J., H.-T. Kao, L. T. Feldman, J. R. Nevins, and S. Strickland. 1984. Common control of the heat shock gene and early adenovirus genes: evidence for a cellular E1A-like activity. Mol. Cell. Biol. 4:867-874.

27. Imperiale, M. J., and J. R. Nevins. 1984. Adenovirus 5 E2 transcription unit: an E1A-inducible promoter with an essential element that functions independently of position or orientation. Mol. Cell. Biol. 4:875-882.

28. Jenkins, J. R., K. Rudge, and G. A. Currie. 1984. Cellular immortalization by a cDNA clone encoding the transformationassociated phosphoprotein p53. Nature (London) 312:651-654.

29. Jones, N., and T. Shenk. 1979. An adenovirus type 5 early gene function regulates expression of other early viral genes. Proc. Natl. Acad. Sci. USA 76:3665-3669.

30. Kao, H.-T., and J. R. Nevins. 1983. Transcriptional activation and subsequent control of the human heat shock gene during adenovirus infection. Mol. Cell. Biol. 3:2058-2065.

31. Keller, J. M., and J. C. Alwine. 1984. Activation of the SV40 late promoter: direct effects of T-antigen in the absence of viral DNA replication. Cell 36:381-389.

32. Kingston, R. E., A. S. Baldwin, Jr., and P. A. Sharp. 1984. Regulation of heat shock protein 70 gene expression by c-myc. Nature (London) 312:280-282.

33. Land, H., L. F. Parada, and R. A. Weinberg. 1983. Tumorigenic conversion of primary embryo fibroblasts requires at least two cooperating oncogenes. Nature (London) 304:596-602.

34. Leff, T., R. Elkaim, C. R. Goding, P. Jalinot, P. Sassone-Corsi,
M. Perricaudet, C. Kodinger, and P. Chambon. 1984. Individual products of the adenovirus $12 \mathrm{~S}$ and $13 \mathrm{~S}$ Ela mRNAs stimulate viral EIIA and EIII expression at the transcriptional level. Proc. Natl. Acad. Sci. USA 81:4381-4385.

35. Lewis, J. B., and M. B. Mathews. 1980. Control of adenovirus early gene expression: a class of immediate early gene products. Cell 21:303-313.

36. Montell, C., E. F. Fisher, M. H. Carruthers, and A. J. Berk. 1982. Resolving the functions of overlapping viral genes by site-specific mutagenesis at a mRNA splice site. Nature (London) 298:380-384

37. Montell, C., E. F. Fisher, M. H. Carruthers, and A. J. Berk. 1984. Complete transformation by adenovirus 2 requires both E1A proteins. Cell 36:951-961.

38. Nevins, J. R. 1981. Mechanism of activation of early viral transcription by the adenovirus E1A gene product. Cell 26:213-220.

39. Newbold, R. F., and R. N. Overell. 1983. Fibroblast immortality is a prerequisite for transformation by the EJ c-Ha-ras oncogene. Nature (London) 304:648-651.

40. Parada, L. F., H. Land, R. A. Weinberg, D. Wolf, and V. Rotter. Cooperation between gene encoding p53 tumor antigen and ras in cellular transformation. Nature (London) 312:649-651.

41. Perricaudet, M., G. Akusjarvi, A. Virtanen, and U. Pettersson. 1979. Structure of two spliced mRNAs from the transforming region of human subgroup $\mathrm{C}$ adenoviruses. Nature (London) 281:694-696.

42. Rassoulzadegan, M., A. Cowie, A. Carr, N. Glaichenhaus, R. Kamen, and F. Cuzin. 1982. The roles of individual polyoma virus early proteins in oncogenic transformation. Nature (London) 300:713-718.

43. Rassoulzadegan, M., Z. Naghashfar, A. Cowie, A. Carr, M. Grisoni, R. Kamen, and F. Cuzin. 1983. Expression of the large $T$ protein of polyoma virus promotes the establishment in culture of "normal" fibroblast cell lines. Proc. Natl. Acad. Sci. USA 80:4354-4358.

44. Ricciardi, R. P., R. L. Jones, C. L. Cepko, P. A. Sharp, and B. E. Roberts. 1981. Expression of early adenovirus genes requires a viral encoded acidic polypeptide. Proc. Natl. Acad. Sci. USA 78:6121-6125.

45. Ruley, H. E. 1983. Adenovirus early region $1 \mathrm{~A}$ enables viral and cellular transforming genes to transform primary cells in culture. Nature (London) 304:602-606.

46. Ruley, H. E., J. F. Moomaw, and K. Maruyama. 1984. Avian myelocytomatosis virus $m y c$ and adenovirus early region $1 \mathrm{~A}$ promote the in vitro establishment of cultured primary cells, $p$. 481-486. In G. F. Van de Woude et al (ed.), Cancer cells 2: oncogenes and viral genes. Cold Spring Harbor Laboratory, Cold Spring Harbor, N.Y.

47. Schrier, P. I., R. Bernards, R. T. M. J. Vaessen, A. Houweling, and A. J. van der Eb. 1983. Expression of class I major histocompatibility antigens switched off by highly oncogenic adenovirus 12 in transformed rat cells. Nature (London) 305:771-775.

48. Shaw, A. R., and E. B. Ziff. 1982. Selective inhibition of adenovirus type 2 early region II and III transcription by an anisomycin block of protein synthesis. Mol. Cell. Biol. 2:789-799.

49. Sodroski, J., C. Rosen, W. C. Goh, and W. Haseltine. 1985. A transcriptional activator protein encoded by the $\mathrm{x}$-lor region of the human T-cell leukemia virus. Science 228:1430-1434.

50. Solnick, D. 1981. An adenovirus mutant defective in splicing from early region 1A. Nature (London) 291:508-510.

51. Solnick, D., and M. A. Anderson. 1982. Transformationdeficient adenovirus mutant defective in expression of region $1 \mathrm{~A}$ but not region 1B. J. Virol. 42:106-113.

52. Spindler, K. R., C. Y. Eng, and A. J. Berk. 1985. An adenovirus early region $1 \mathrm{~A}$ protein is required for maximal viral DNA replication in growth-arrested human cells. J. Virol. 53:742-750.

53. Svensson, C., and G. Akusjarvi. 1984. Adenovirus 2 early region 1A stimulates expression of both viral and cellular genes. EMBO J. 3:789-794.

54. Triesman, R., M. R. Green, and T. Maniatis. 1983. Cis and 
Trans-activation of globin transcription in transient assays. Proc. Natl. Acad. Sci. USA 80:7428-7432.

55. Triesman, R., U. Novak, J. Favalovo, and R. Kamen. 1981 Transformation of rat cells by an altered polyoma virus genome expressing only the middle $T$ protein. Nature (London) 292:595-600.

56. Velcich, A., and E. Ziff. 1975. Adenovirus Ela proteins repress transcription from the SV40 early promoter. Cell 40:705-716.

57. Virtanen, A., and U. Pettersson. 1983. The molecular structure of the 9S mRNA from early region 1A of adenovirus serotype 2 . J. Mol. Biol. 165:496-499.

58. Weeks, D. L., and N. C. Jones. 1983. E1A control of gene expression is mediated by sequences $5^{\prime}$ to the transcriptional starts of the early viral genes. Mol. Cell. Biol. 3:1222-1234.

59. Wigler, M., A. Pellicer, S. Silverstein, R. Axel, G. Urlaub, and L. Chasin. 1979. DNA-mediated transfer of the adenine phosphoribosyltransferase locus into mammalian cells. Proc. Natl. Acad. Sci. USA 76:1373-1376.

60. Winsberg, G., and T. Shenk. 1984. Dissection of overlapping functions within the adenovirus type 5 E1A gene. EMBO J. 3:1907-1912.

61. Zinn, K., D. DiMaio, and T. Maniatis. 1983. Identification of two distinct regulatory regions adjacent to the human beta interferon gene. Cell 34:865-879. 